\title{
Malignant Lymphoma Arising from Heterotopic Warthin's Tumor in the Neck: Case Report and Review of the Literature
}

\author{
Shigeki Gorai, ${ }^{1}$ Tsutomu Numata, ${ }^{2}$ Sawako Kawada, ${ }^{2}$ Masayuki Nakano, ${ }^{3}$ \\ Jun-ICHI TAMARU ${ }^{4}$ and TOSHIMITSU KOBAYASHI ${ }^{1}$ \\ ${ }^{1}$ Department of Otolaryngology-Head and Neck Surgery, Tohoku University Graduate School of \\ Medicine, Sendai, Japan \\ ${ }^{2}$ Department of Otolaryngology, National Hospital Organization Chiba Medical Center, Chiba, \\ Japan \\ ${ }^{3}$ Department of Surgical Pathology, National Hospital Organization Chiba Medical Center, Chiba, \\ Japan \\ ${ }^{4}$ Department of Pathology, Saitama Medical Center, Saitama Medical University, Saitama, Japan
}

Gorai, S., Numata, T., Kawada, S., Nakano, M., Tamaru, J. and Kobayashi, T. Malignant Lymphoma Arising from Heterotopic Warthin's Tumor in the Neck: Case Report and Review of the Literature. Tohoku J. Exp. Med., 2007, 212 (2), 199-205 Warthin's tumor (WT), so-called adenolymphoma, is a benign salivary gland tumor with both epithelial and lymphoid histological characteristics, so the histogenesis remains unclear. Treatment consists primarily of tumor removal or conservative follow up. Here we present a rare case of malignant lymphoma arising from heterotopic (ectopic) WT. A 102-year-old man presented with a mass in the left side of the neck which was painless but gradually enlarged over 1 month. The mass was $2-3 \mathrm{~cm}$ in diameter, and freely moveable below the angle of the mandible. The mass was totally removed. The histological diagnosis was malignant lymphoma, diffuse large B-cell type, arising from heterotopic WT. Postoperative staging examination including chest radiography, bone scan, and computed tomography of the abdomen and pelvis revealed no evidence of dissemination of malignant lymphoma. Malignant transformation within WT is rarer in the lymphoid component than in the epithelial component. Only 16 cases of malignant transformation arising from WT have been reported, including only three cases of non-Hodgkin lymphoma apparently arising from heterotopic WT. Tumor removal or careful follow up is recommended in patients with WT because of the potential risk posed by such malignant transformation. heterotopic; ectopic; adenolymphoma; Warthin's tumor; malignant lymphoma

(C) 2007 Tohoku University Medical Press

Warthin's tumor (WT), also known as adenolymphoma, papillary cystadenoma, cystadenolymphoma, and epitheliolymphoid cyst, is a com- mon benign tumor of the parotid glands which may occur synchronously or metachronously in the same or contralateral gland, so may be associ-

Received November 20, 2006; revision accepted for publication April 17, 2007.

Correspondence: Shigeki Gorai, M.D., Department of Otolaryngology-Head and Neck Surgery, Tohoku

University Graduate School of Medicine, 1-1 Seiryo-machi, Aoba-ku, Sendai 980-8574, Japan.

e-mail: gorai@orl.med.tohoku.ac.jp 
ated with recurrence. WT is rare in the submandibular or minor salivary glands. WT is generally a disease of middle aged and elderly men, with the highest incidence in the 6th to 7 th decades. WT is the second most common neoplasm of the salivary gland, accounting for up to $5-11 \%$ of primary tumors (Ellis and Auclair 1995). WT causes up to $25 \%$ of parotid tumors in the Asian population, and the male:female ratio is 4.6:1 (Chung et al. 1999). However, the frequency of WT varies greatly with ethnicity (Ellis and Auclair 1995).

Treatment consists primarily of tumor removal and superficial parotidectomy, or conservative follow up. Histologically, WT consists of a glandular epithelial component with the characteristic eosinophilic cytoplasm, and a lymphoid stroma which may form large ovoid follicles containing monotonous proliferation of small cleaved follicular center cells and scattered larger transformed lymphocytes. WT shows variable epithelial differentiation and ratio of epithelial component to lymphoid stroma (Seifert et al. 1980). Malignant change is rare in the epithelial component, but more frequent in the lymphoid component.

Here we present an extremely rare case of heterotopic (ectopic) WT involving non-Hodgkin lymphoma (NHL) in the neck.

\section{Case Report}

A 102-year-old man visited an ear, nose, and throat clinic in January 2005 because of a mass in the left side of the neck persisting for 1 month. The mass was painless and non-tender, but had been increasing in size gradually. His history was unremarkable, except for hypertension and prostatomegaly. Physical examination revealed a tumor approximately $3 \mathrm{~cm}$ below the left angle of the mandible. The mass was $2-3 \mathrm{~cm}$ in diameter, and freely moveable. The patient had no other symptoms and denied weight loss, fever, chills, or night sweats. The remainder of the physical examination and all laboratory test results were within normal limits except for mild anemia.

Ultrasonography showed a well-defined hypoechoic mass with a central hyperechoic lesion, measuring $20 \mathrm{~mm} \times 32 \mathrm{~mm} \times 24 \mathrm{~mm}$ (Fig. 1). Ultrasonography-guided fine needle aspiration biopsy of the central lesion indicated class II, or no malignancy. Color Doppler ultrasonography showed relatively rich vascularization, but no other cervical lymphadenopathy.

The tumor was located under the platysma, in the left side of the neck. The mass was easily extirpated and had no communication with the submandibular gland, parotid gland, or skin. The excised tumor was soft and well encapsulated, and the cut surface was grayish-brown. No other

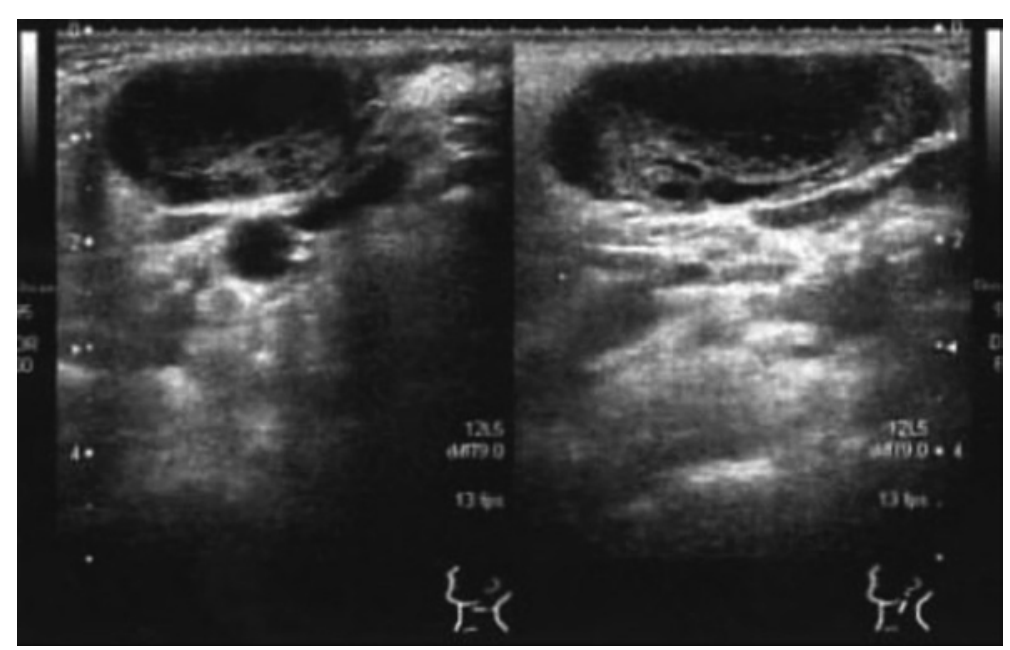

Fig. 1. Ultrasonography scans on admission. A well-defined hypoechoic mass is shown. 
cervical lymphadenopathy was found.

Histological examination revealed a combination of WT and NHL. Postoperative staging examination including chest radiography, bone scan, and computed tomography of the abdomen and pelvis revealed no evidence of dissemination of malignant lymphoma, nodal swelling, or hepatosplenomegaly. Hematological and biochemical investigations showed increased soluble interleukin-2 receptor level $(1,060 \mathrm{U} / \mathrm{ml}$; normal value 220-530 U/ml). Other evaluations were almost within normal limits. The Ann Arbor stage was not clear, because the clinical workup was incomplete, and bone marrow aspiration had not been done.

No therapy was initiated on account of the patient's physical condition and his advanced age. The patient was periodically followed up by ultrasonography. Four months after the diagnosis, he presented with multiple lymphadenopathies in both sides of the neck. The soluble interleukin-2 receptor level was increased $(1,450 \mathrm{U} / \mathrm{ml})$.

The patient was treated with combination chemotherapy (CHOP) using cyclophosphamide (300 mg on day 1), adriamycin (30 mg on day 1), vincristine (1.0 mg on day 1$)$, and prednisone (30 $\mathrm{mg}$ on days 1 to 5). The dosage was one-third of the normal. Following two cycles of this CHOP

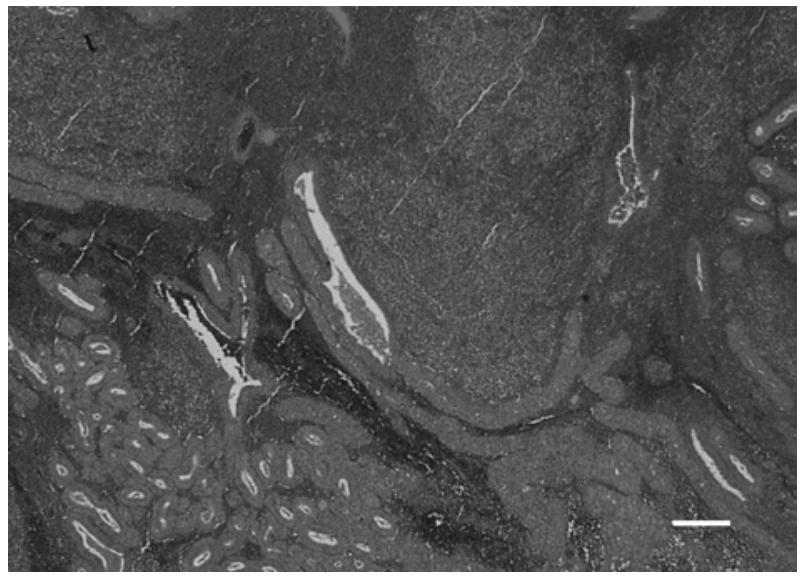

Fig. 2. Photomicrograph of the tumor specimen.

Low power view demonstrating typical Warthin's tumor structure (left), and malignant lymphoma arising in the lymphoid stroma (top right).

Hematoxylin-eosin stain. bar $=0.2 \mathrm{~mm}$. chemotherapy, the multiple lymphadenopathies in his neck had regressed almost to normal size. However, whole body debility advanced gradually, and he died 10 months after the initial diagnosis.

Histological examination of the surgical specimen showed the classical composite appearance of WT (Figs. 2-4). The epithelial component

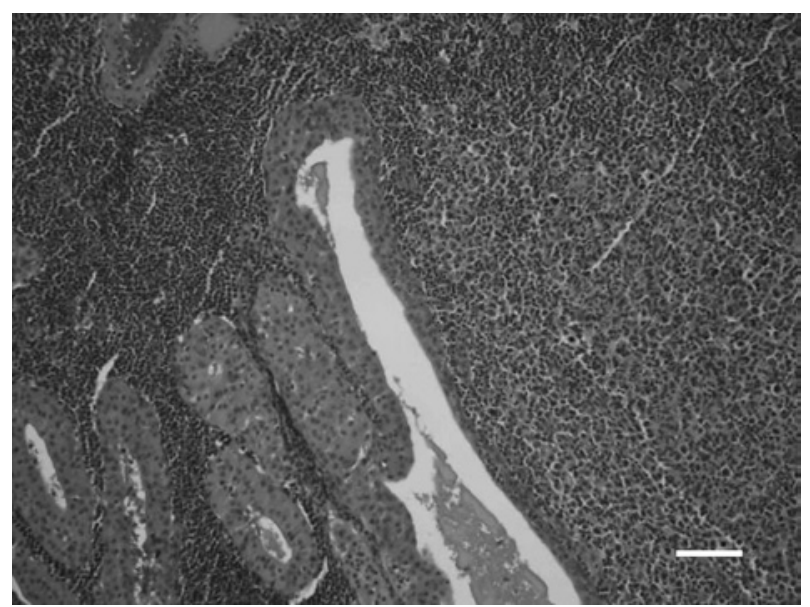

Fig. 3. Photomicrograph of the tumor specimen. Middle power view demonstrating typical lymphoid stroma (left), epithelium of Warthin's tumor structure (center), and atypical lymphoid cells infiltrating the lymphoid stroma (right) Hematoxylin-eosin stain. bar $=0.05 \mathrm{~mm}$.

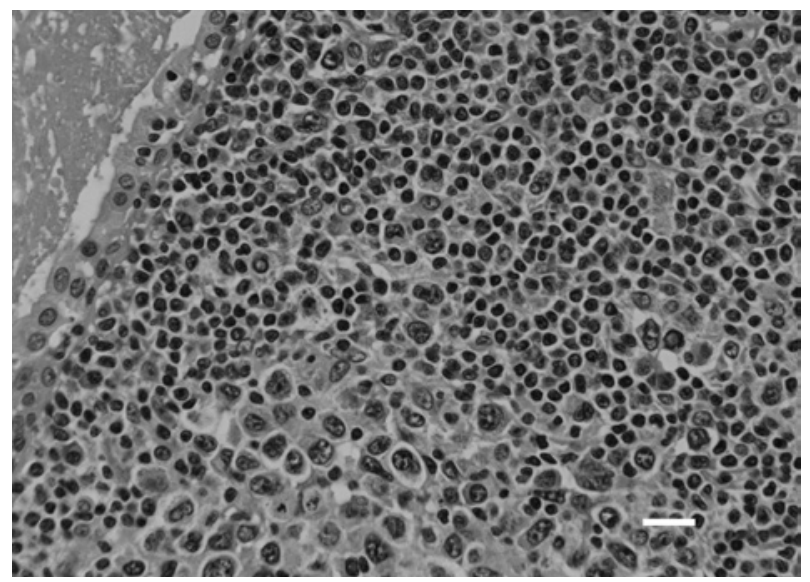

Fig. 4. Photomicrograph of the tumor specimen. High power view demonstrating diffuse infiltration of the stroma by large atypical lymphoid cells with irregular size. The transitional zone of large and medium size cells is seen. Hematoxylin-eosin stain. bar $=0.02 \mathrm{~mm}$. 


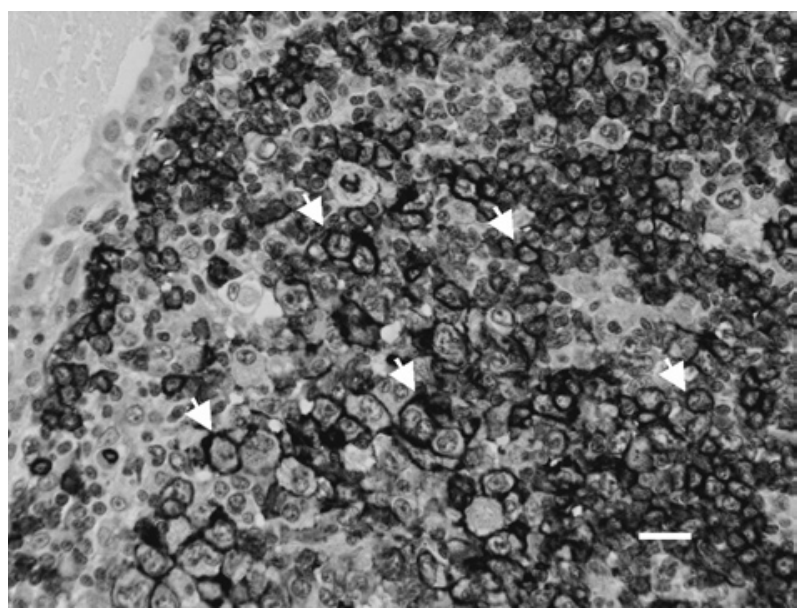

Fig. 5. Photomicrograph of the tumor specimen. Arrows indicate the tumor cells showing expression of CD20. $\mathrm{bar}=0.02 \mathrm{~mm}$.

consisted of a double layer of tall columnar cells with granular acidophilic cytoplasm which formed regular glandular spaces with broad or fine papillae. The abundant lymphoid stroma was partially replaced by lymphoma cells, and ReedSternberg cells were not found.

Immunohistochemical examination of the large neoplastic cells showed positive reaction for CD20, CD79a, and B cell-specific activator protein (paired box gene-5), and negative reaction for CD3, CD5, CD10, CD15, and CD30. The neoplastic cells were diffusely and strongly positive for CD20 (Fig. 5) and negative for CD3. These findings strongly suggest B-cell lineage. The final histological diagnosis was malignant lymphoma, diffuse large B-cell type, arising from heterotopic WT. Clonality study or in situ hybridization may be useful for precise diagnosis. They should be performed in future.

\section{Discussion}

Carcinoma arising in a pleomorphic adenoma is well known, but malignant transformation within WT is rare (Nagao et al. 1981). The incidence of WT was $11.5 \%$ of all parotid tumors and the incidence of malignant transformation in WT was $1.1 \%$ in one series (Nagao et al. 1998). Malignant transformation is rarer in the lymphoid component than the epithelial component to our knowledge. Malignant lymphoma apparently arising in the lymphoid component is extremely rare. Some cases have no remnant of the lymphoid component, which normally occurs in WT, as this was totally replaced by malignant lymphoma in the advanced disease. In our case, the epithelial component was clearly recognizable, showed no significant abnormalities, and the lymphoid component was partially replaced by NHL. Furthermore, the NHL arose from heterotopic WT, so our case is extremely unusual.

\section{Heterotopic salivary gland and neoplasms}

Heterotopic salivary gland refers to the presence of salivary tissue at sites other than the three major salivary glands and the minor salivary glands. Heterotopic salivary gland tissue may occur in the lymph nodes, external auditory canal, thyroglossal duct cyst, hypophysis, mandible, mastoid bone, middle ear, tongue, sternoclavicular joint, thyroid, parathyroid glands, and in the upper and lower neck regions (Pesavento and Ferlito 1976; Ferlito et al. 1999). Cervical heterotopic salivary tissue or neoplasm may present as a mass, cyst, or sialo-cutaneous fistula (draining sinus). Salivary gland in the cervical lymph node is uncommon, but the incidence of salivary heterotopia in the parotid lymph nodes has been reported as $67.7 \%$ (Shinohara et al. 1992), 25\% (Seifert and Geiler 1956). On the other hand, the incidence of salivary heterotopia in extraparotid lymph node is rather low at $12.2 \%$ (Shinohara et al. 1992).

Condensation of mesenchyma may occur as a later event, and as a result, either lymph nodes are trapped within the parotid gland or salivary gland is included within the paraparotid lymph nodes (Singer et al. 1979). This hypothesis explains the presence of heterotopic salivary tissue in the upper neck and periparotid regions. On the other hand, there may be a relationship to the brachial apparatus, specifically, the cervical sinus of His. Defective closure of the sinus with salivary gland tissue arising from heteroplasia of ectodermal lining of the sinus remnant is a plausible explanation for salivary heterotopia (Youngs and Scofield 1967), and may explain the appear- 
ance of salivary tissue in the lower neck. Clearly there is a close relationship between the parotid salivary gland and lymphoid tissue.

Reviews of neoplasms arising from the heterotopic salivary glands found that approximately $60-80 \%$ of heterotopic salivary tumors are benign, and mainly occur in adults, with few pediatric cases (Ferlito et al. 1999; Daniel and McGuirt 2005). WT is the most frequent neoplasm, followed by pleomorphic adenoma. On the other hand, mucoepidermoid carcinoma was the most common malignant neoplasm. The most popular hypothesis for the pathogenesis of WT is neoplastic proliferation of heterotopic salivary ducts, which are present in the pre-existing intraparotid or paraparotid lymphoid tissue (Seifert et al. 1980). Heterotopic salivary gland tissue can be localized in the cervical lymph nodes. Except for WT, primary salivary gland tumors rarely develop in the lymph nodes of the parotid gland or the cervical lymph nodes. WT is accepted to occur in $8 \%$ of cervical lymph nodes (Snyderman et al.
1986). In a sense, WT may be more a lesion of the lymph nodes than the salivary glands.

\section{WT and its malignant transformation}

Examples of WT associated with disseminated NHL or Hodgkin's disease have been reported (Seifert et al. 1980), although first detection of malignant lymphomas in the lymphoid stroma of WT is less common. Most of the 16 reported cases were NHL (Table 1). Malignant transformation occurring in WT is unusual.

In contrast, malignant lymphomas are not rare in patients with primary immune sialadenitis with or without other symptoms of Sjögren's syndrome. Patients with Sjögren's syndrome have a high risk of developing malignant lymphoma, 40 times higher than in the normal population, so the lymphoma seems more likely to involve the WT secondarily. Malignant lymphoma arising from the salivary gland accounts for $40 \%$ of malignant lymphoma of the head and neck, and $5 \%$ of all extranodal lymphoma in such patients. The NHL:

TABlE 1. Summary of cases of malignant lymphoma associated with Warthin's tumor.

\begin{tabular}{lclll}
\hline Reference & year & $\begin{array}{l}\text { Sex/ } \\
\text { Age (y) }\end{array}$ & $\begin{array}{l}\text { Location } \\
\text { of tumor }\end{array}$ & Histology \\
\hline Colby and Dorfman & 1979 & M/52 & Parotid & Nodular poorly differentiated lymphocytic (NHL) \\
& & NA & NA & Unclassified \\
Miller et al. & 1982 & M/49 & Angle of mandible & Small cleaved follicular center,partially follicular (NHL) \\
Banik et al. & 1985 & M/75 & Parotid & Centroblastic-centrocyte; diffuse (NHL) \\
& & M/76 & Parotid & Centroblastic-centrocyte; partially follicular (NHL) \\
Hall et al. & 1985 & M/64 & Parotid & Follicular center cell type; diffuse (NHL) \\
Melato et al. & 1986 & M/69 & Parotid & Mixed cellularity (HD) \\
Griesser et al. & 1986 & F/64 & Palate & Centroblastic-centrocyte; low grade; follicular (NHL) \\
Bunker and Locker & 1989 & M/82 & Submandibular & Centroblastic-centrocyte; high grade; follicular (NHL) \\
Medeiros et al. & 1990 & F/63 & Parotid & B-cell small lymphocytic (NHL) \\
Giardini and Mastore & 1990 & M/57 & Parotid & Follicle center lymphoma (NHL) \\
& & M/71 & Parotid & Centroblastic-centrocytic follicular (NHL) \\
Shikhani et al. & 1993 & M/56 & Parotid & Intermingled small and large cells of mixed (NHL) \\
Park et al. & 2000 & F/68 & Periparotid LN & Follicle center lymphoma (NHL) \\
& & M/55 & Parotid & Follicle center lymphoma (NHL) \\
Saxena et al. & 2005 & M/55 & Parotid & Small lymphocytic lymphoma (NHL) \\
Present case & & M/102 & Neck LN & Diffuse large B-cell lymphoma (NHL) \\
\hline
\end{tabular}

HD, Hodgkin disease; NHL, non-Hodgkin lymphoma; NA, not available; LN, lymph node. 
Hodgkin's disease ratio is $85: 15$ in salivary gland lymphomas (Seifert 1991). The occurrence of malignant tumor in accessory parotid gland is much higher than in the main parotid gland (Johnson and Spiro 1979). Whether heterotopic WT is more likely to transform into malignant lymphoma than WT in the main salivary glands remains unclear, because cases which can be identified as NHL initially arising from WT are extremely rare.

The pathogenesis of the malignant transformation of WT is still unknown, but the effect of radiation exposure on the salivary gland is of special interest. Metaplasia in the epithelial component of WT was found in $7.5 \%$ of one series, suggesting a relationship with the past irradiation history (Seifert et al. 1980). A review of the incidence and pathology of malignant and benign salivary gland tumors after high radiation exposure caused by atomic bomb blast included a case of mucoepidermoid carcinoma associated with preexisting WT (Saku et al. 1997). The relationship of NHL arising from WT to previous radiation therapy has been discussed by several authors. In our case, the patient had no history of radiotherapy, so there may be other unknown factors.

The relationship between WT and interleukin-2 receptor level remains unclear. Reported cases have not shown the values. Our cases of WT have shown various values. However, inflammatory rapid swelling is often seen in patients with WT. Therefore, increased interleukin-2 receptor level is quite possible in such a situation. Further examination will be necessary to clarify this point.

\section{Treatment of heterotopic salivary gland}

Malignant transformation of the individual components of WT may be considered rare but not exceptional. The initial appearance of malignant lymphomas is frequently in the lymph nodes of the cervical region. Only four cases of malignant lymphoma have arisen from heterotopic WT in the neck. Such cases are rare and may be mistaken as malignant lymphomas arising from the cervical lymph nodes. The lymphoid stroma of WT is part of the systemic lymphoid tissue, so is likely to be involved in disseminated lymphoma. In the advanced stages, the distinction between primary and secondary lymphomas of the salivary gland may be impossible. Heterotopic salivary tissue in the cervical region is probably more common than previously recognized histologically. Neoplasms arising from heterotopic salivary tissue should be considered in the differential diagnosis for isolated neck masses. Accurate diagnosis can only be established after removal. Even if heterotopic salivary lesion presents with no symptom, early removal with careful and periodical follow up is recommended, especially in long-term progressive or pediatric cases.

\section{Acknowledgments}

We wish to thank Dr. Kouichi Nagao for his assistance.

\section{References}

Banik, S., Howell, J.S. \& Wright, D.H. (1985) Non-Hodgkin's lymphoma arising in adenolymphoma-a report of two cases. J. Pathol., 146, 167-177.

Bunker, M.L. \& Locker, J. (1989) Warthin's tumor with malignant lymphoma. DNA analysis of paraffin-embedded tissue. Am. J. Clin. Pathol., 91, 341-344.

Chung, Y., Khoo, M., Heng, M., Hong, G. \& Soo, K. (1999) Epidemiology of Warthin's tumour of the parotid gland in an Asian population. Br. J. Surg., 86, 661-664.

Colby, T.V. \& Dorfman, R.F. (1979) Malignant lymphomas involving the salivary glands. Pathol. Annu., 14, 307-324.

Daniel, E. \& McGuirt, W.F. (2005) Neck masses secondary to heterotopic salivary gland tissue: a 25 -year experience. Am. J. Otolaryngol., 26, 96-100.

Ellis, G. \& Auclair, P. (1995) Tumors of the major salivary glands. In: Atlas of Tumor Pathology, 3rd series, fascicle 17. Armed Forces Institute of Pathology, Washington, DC, pp. 68-79.

Ferlito, A., Bertino, G., Rinaldo, A., Mannara, G.M. \& Devaney, K.O. (1999) A review of heterotopia and associated salivary gland neoplasms of the head and neck. J. Laryngol. Otol., 113, 299-303.

Giardini, R. \& Mastore, M. (1990) Follicular non Hodgkin's lymphoma in adenolymphoma: report of a case. Tumori, 76, 212-215.

Griesser, G.H., Hansmann, M.L., Bogman, M.J., Pielsticker, K. \& Lennert, K. (1986) Germinal center derived malignant lymphoma in cystadenolymphoma. Virchows Arch. A. Pathol. Anat. Histopathol., 408, 491-496.

Hall, G., Tesluk, H. \& Baron, S. (1985) Lymphoma arising in an adenolymphoma. Hum. Pathol., 16, 424-427.

Johnson, F.E. \& Spiro, R.H. (1979) Tumors arising in accessory parotid tissue. Am. J. Surg., 138, 576-578.

Medeiros, L.J., Rizzi, R., Lardelli, P. \& Jaffe, E.S. (1990) Malignant lymphoma involving a Warthin's tumor: a case with immunophenotypic and gene rearrangement analysis. Hum. Pathol., 21, 974-977. 
Melato, M., Falconieri, G., Fanin, R. \& Baccarani, M. (1986) Hodgkin's disease occurring in a Warthin's tumor: first case report. Pathol. Res. Pract., 181, 615-620.

Miller, R., Yanagihara, E.T., Dubrow, A.A. \& Lukes, R.J. (1982) Malignant lymphoma in the Warthin's tumor. Report of a case. Cancer, 15, 2948-2950.

Nagao, K., Matsuzaki, O., Saiga, H., Sugano, I., Shigematsu, H. \& Kaneko, T. (1981) Histopathologic studies on carcinoma in pleomorphic adenoma of the parotid gland. Cancer, $\mathbf{4 8}$, 113-121.

Nagao, T., Sugano, I., Ishida, Y., Tajima, Y., Furuya, N. \& Kondo, Y. (1998) Mucoepidermoid carcinoma arising in Warthin's tumour of the parotid gland: report of two cases with histopathological, ultrastructural and immunohistochemical studies. Histopathology, 33, 379-386.

Park, C.K., Manning, J.T. Jr, Battifora, H. \& Medeiros, L.J. (2000) Follicle center lymphoma and Warthin tumor involving the same anatomic site. Report of two cases and review of the literature. Am. J. Clin. Pathol., 113, 113-119.

Pesavento, G. \& Ferlito, A. (1976) Benign mixed tumour of heterotopic salivary gland tissue in upper neck. Report of a case with a review of the literature on heterotopic salivary gland tissue. J. Laryngol. Otol., 90, 577-584.

Saku, T., Hayashi, Y., Takahara, O., Matsuura, H., Tokunaga, M. \& Tokunaga, M. (1997) Salivary gland tumors among atomic bomb survivors. 1950-1987. Cancer, 79, 1465-1475.

Saxena, A., Memauri, B. \& Hasegawa, W. (2005) Initial diag- nosis of small lymphocytic lymphoma in parotidectomy for Warthin tumour, a rare collision tumour. J. Clin. Pathol., 58, 331-333.

Seifert, G. (1991) Histological typing of salivary gland tumors. In: International Histological Classification of Tumors, 2nd ed., World Health Organization, pp. 32-33.

Seifert, G., Bull, H. \& Donath, K. (1980) Histologic subclassification of the cystadenolymphoma of the parotid gland. Analysis of 275 cases. Virchows Arch. A Pathol. Anat. Histol., 388, 13-38.

Seifert, G. \& Geiler, G. (1956) Zur Pathologie der kindlichen Kopfspeicheldrusen. Zieglers Beitr, 116, 1-38. (in German)

Shikhani, A.H., Shikhani, L.T., Kuhajda, F.P. \& Allam, C.K. (1993) Warthin's tumor-associated neoplasms: report of two cases and review of the literature. Ear Nose Throat J., 72, 264-269, 272-273.

Shinohara, M., Harada, T., Nakamura, S., Oka, M. \& Tashiro, H. (1992) Heterotopic salivary gland tissue in lymph nodes of the cervical region. Int. J. Oral. Maxillofac. Surg., 21, 166-171.

Singer, M.I., Applebaum, E.L. \& Loy, K.D. (1979) Heterotopic salivary tissue in the neck. Laryngoscope, 89, 1772-1778.

Snyderman, C., Johnson, J.T. \& Barnes, E.L. (1986) Extraparotid Warthin's tumor. Otolaryngol. Head Neck Surg., 94, $169-175$.

Youngs, L.A. \& Scofield, H.H. (1967) Heterotopic salivary gland tissue in the lower neck. Arch. Pathol., 83, 550-556. 